\title{
OPTIMASI KAPASITAS PEMBANGKIT LISTRIK TENAGA HIBRIDA MENGGUNAKAN HOMER DI TPA GAMPONG JAWA BANDA ACEH
}

\author{
Mahdi Syukri ${ }^{1}$, Dedy Yuliadi $^{2}$, Syahrizal \\ ${ }^{1}$ Jurusan Teknik Elektro dan Komputer, Fakultas Teknik, Universitas Syiah Kuala \\ Jl. Tgk. Syech Abdurrauf No. 7 Darussalam, Banda Aceh 23111, Indonesia \\ ${ }^{1}$ Email: mahdisyukri@unsyiah.ac.id \\ ${ }^{2}$ Email: dj.juliadi@mhs.unsyiah.ac.id \\ ${ }^{3}$ Email: syahrizal@unsyiah.ac.id
}

\begin{abstract}
ABSTRAK
Saat ini pasokan energi listrik masih belum terpenuhi pada sebagian daerah dikarenakan semakin menipisnya sumber energi konvensional dan energi fosil. Energi alternatif yang ideal adalah energi terbarukan. Tempat Pembuangan Akhir (TPA) Gampong Jawa Banda Aceh memiliki potensi pembangkit listrik tenaga biomasa (PLTBm) dikarenakan memiliki banyak sampah dengan rata-rata produksi 250 ton per hari. Berdasarkan titik koordinat TPA Gampong Jawa, Banda Aceh menggunakan simulasi HOMER diperoleh nilai radiasi matahari (Photovoltaic) sebesar $4,12 \mathrm{kWh} / \mathrm{m}^{2} /$ hari. Tujuan dari penilitian ini adalah memperoleh jumlah energi potensi biomassa dan photovoltaic serta model yang optimal untuk sistem pembangkit listrik hibrida di TPA Gampong Jawa. Dari hasil penilitian ini potensi daya listrik dari pembangkit biomassa di TPA Gampong Jawa, yaitu $2000 \mathrm{~kW}$ yang dapat menghasilkan energi listrik dalam satu tahun yaitu 12.641.232 kWh. Ada tiga skenario yang digunakan untuk mensimulasikan model Pembangkit Tenaga Listrik Hibrid (PLTH). Model yang paling optimal adalah skenario 3 dengan nilai Net Present Cost (NPC) dan Cost of Energy (COE) yang terkecil. Nilai Net Present Cost (NPC) dan COE masing-masing adalah \$ 42.698.527 dan \$0,2614 dimana biomassa dan photovoltaic menghasilkan energi listrik masing-masing 11.753.607 $\mathrm{kWh}$ per tahun dan 1.248.080 kWh per tahun, generic $1 \mathrm{kWh}$ Lead Acid 300 unit dan converter $720 \mathrm{~kW}$.
\end{abstract}

Kata Kunci: Biomassa, Hibrida, Homer. 


\begin{abstract}
Currently the supply of electrical energy is still not fulfilled in some areas due to the depletion of conventional energy sources and fossil energy. The ideal alternative energy is renewable energy. The Final Disposal Site (TPA) of Gampong Jawa Banda Aceh has the potential for a biomass power plant (PLTBm) because it has a lot of waste with an average production of 250 tons per day. Based on the coordinates of the TPA Gampong Jawa, Banda Aceh using the HOMER simulation, the solar radiation value (Photovoltaic) was obtained at $4.12 \mathrm{kWh} / \mathrm{m}^{\wedge} 2 /$ day. The purpose of this research is to obtain the optimal amount of biomass and photovoltaic potential energy and the optimal model for the hybrid power generation system in TPA Gampong Jawa. From the results of this study, the potential for electrical power from the biomass generator in TPA Gampong Jawa, which is $2000 \mathrm{~kW}$ which can produce electrical energy in one year, is 12,641,232 $\mathrm{kWh}$. There are three scenarios used to simulate a model of a Hybrid Electric Power Plant (PLTH). The most optimal model is scenario 3 with the smallest Net Present Cost (NPC) and Cost of Energy (COE) values. The Net Present Cost (NPC) and COE values are \$ 42,698,527 and \$ 0.2614 respectively where biomass and photovoltaic produce 11,753,607 $\mathrm{kWh}$ of electrical energy per year and 1,248,080 kWh per year, generic $1 \mathrm{kWh}$ Lead Acid 300 units and converter 720 $k W$.
\end{abstract}

Keywords: Biomass, Hybrid, Homer

\title{
I. PENDAHULUAN
}

Saat ini pasokan energi masih belum terpenuhi pada sebagian daerah dikarenakan semakin menipisnya sumber energi konvensional dan energi fosil. Energi alternatif yang ideal adalah energi terbarukan, dimana energi tersebut tidak berpotensi habis seperti energi matahari, panas dan lain-lain (Md Saleh Ebn Sharif, 2017).

Gampong Jawa yang merupakan salah satu gampong di Banda Aceh memiliki Tempat Pembuangan Akhir (TPA) dengan luas $21 \mathrm{Ha}$ menghasilkan sampah sebesar 250 ton/hari. Berdasarkan data badan antariksa Amerika Serikat (NASA, 2015) TPA Gampong Jawa memiliki radiasi matahari dengan radiasi pertahun sebesar $4,12 \mathrm{kWh} / \mathrm{m}^{2} /$ hari.

Desain sistem hibrida yang efisien dan handal diperoleh berdasarkan kombinasi yang benar dari sumber energi terbarukan, kondisi iklim daerah yang diteliti dan biaya awal komponen sistem. Untuk mencapai solusi yang optimal penilitian intensif telah dilakukan seperti pada (A. Giwa, A. Alabi, 2017. (E. Romero-Cadaval, dkk, 2015. Haryanto, 2018. Tanim, M, 2014).

\section{DASAR TEORI}

A. Pembangkit Listrik Tenaga Hibrida 
Pembangkit Listrik Tenaga Hibrida adalah penggabungan dari beberapa energi listrik yang menggabungkan antara terbarukan dan konvensional. Pembangkit listrik hibrida ini biasanya menggunakan energi terbarukan dari energi matahari dan energi biomassa. Kedua pembangkit dioperasikan dan dihubungkan melalui konverter untuk dihubungkan ke beban seperti pada gambar 1 di bawah ini.

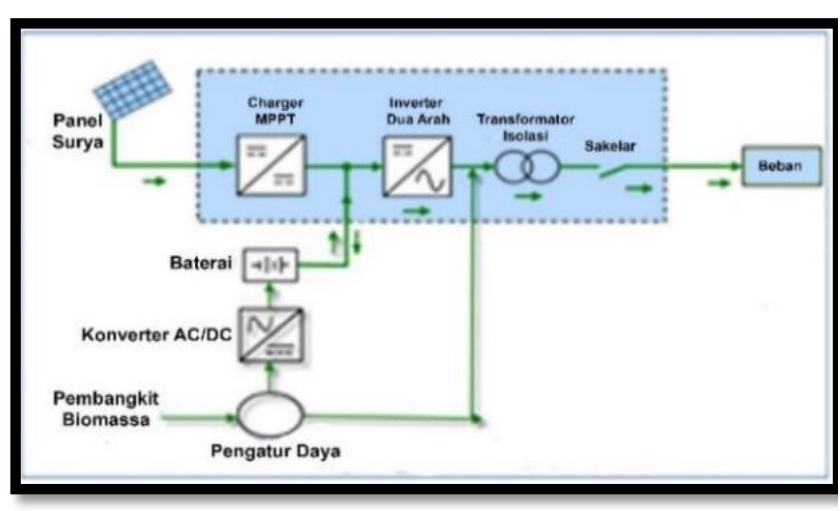

Gambar 1 Konfigurasi PLTH PV-Biomassa

\section{B. Perangkat Lunak HOMER}

Perangkat lunak microgrid energi adalah standar global untuk mengoptimalkan desain microgird di semua sector mulai dari listrik desa dan utilitas pulau hingga kampus-kampus yang terhubung dengan jaringannya. Awalnya dikembangkan di Lab Energi terbarukan Nasional dan disempurnakan serta didistribusikan oleh HOMER Energy; HOMER (Model pengoptimalan Hibrid untuk banyak sumber daya energi) menumpuk tiga alat canggih dalam satu produk perangkat lunak, sehingga dapat mengoptimalkan dari segi teknis dan ekonomisnya [7].

\section{Analisis Sensitivitas}

Dalam proses analisis sensitivitas HOMER software akan mengulangi proses optimasi dari setiap variable sensitivitas yang telah ditentukan.

\section{METODE PENELITIAN}

Alur penilitian simulasi pemodelan PLTH sebagai berikut :
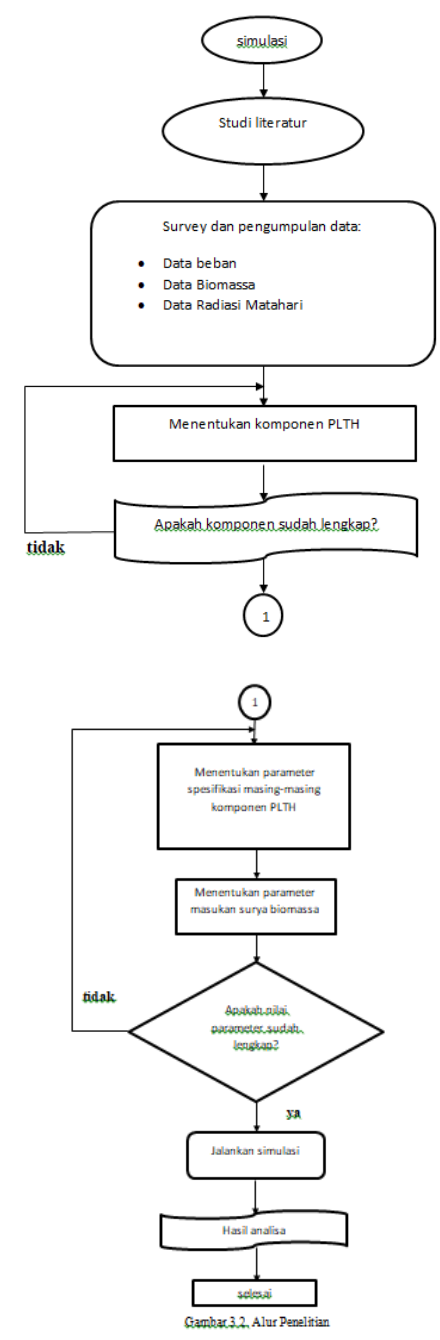

Gambar 2 Diagram Alir tahapan Penilitian

A. Bahan Penelitian

Bahan penilitian yang dibutuhkan adalah : Data beban harian, data biomassa, data radiasi Matahari pada TPA Gampong Jawa dan juga software HOMER untuk dapat melakukan 
simulasi dan pengoptimalan pembangkit listrik tenaga hibrida.

\section{B. Alat Penilitan}

Alat yang digunakan untuk melakukan penilitian adalah Personal Computer (PC) dengan software HOMER untuk melakukan simulasi dan optimasi pembangkit tenaga hybrid.

\section{Studi literature}

Studi literatur dilakukan dengan cara mecari serta mempelajari secara teori-teori, informasi dan data yang berhubungan dengan penilitian, hasilnya digunakan sebagai landasan logika berfikir dalam menyelesaikan masalah secara ilmiah. Landasarn ini dapat diperoleh dari berbagai sumber yang relevan seperti buku, jurnal maupun publikasi ilmiah.

\section{Data Masukan}

Data masukan pada penilitian ini berupa data beban harian, Data biomassa dan intensitas radiasi.

a) Data Masukan Beban Harian

Data Masukkan beban harian pada TPA Gampong Jawa yang didapat dari HOMER

\begin{tabular}{|c|c|}
\hline 2 & 1.469 \\
\hline 3 & $1.434,24$ \\
\hline 4 & $1.442,79$ \\
\hline 5 & $1.406,1$ \\
\hline 6 & $1.392,99$ \\
\hline 7 & $1.362,85$ \\
\hline 8 & $1.292,09$ \\
\hline 9 & $1.286,85$ \\
\hline 10 & $1.307,81$ \\
\hline 11 & $1.383,82$ \\
\hline 12 & $1.385,13$ \\
\hline 13 & $1.381,2$ \\
\hline 14 & $1.395,61$ \\
\hline 15 & $1.374,65$ \\
\hline 16 & $1.429,68$ \\
\hline 17 & 1.493 .9 \\
\hline 18 & 14399 \\
\hline 19 & $1.439,9$ \\
\hline 20 & $1.644,6$ \\
\hline 21 & $1.618,39$ \\
\hline 22 & $1.596,11$ \\
\hline 23 & $1.534,52$ \\
\hline
\end{tabular}
sebagai berikut:

Tabel 1 Profil Beban Harian

\begin{tabular}{|c|c|}
\hline Jam & $\begin{array}{c}\text { Beban } \\
\text { Listrik }(\mathrm{kW})\end{array}$ \\
\hline 0 & $1.552,87$ \\
\hline 1 & $1.509,62$ \\
\hline
\end{tabular}

Pada tabel 1 di atas merupakan beban harian yang dapat digunakan untuk mensimulasikan beban listrik selama setahun. Simulasi yang dimodelkan dalam sistem hibrida ini dapat diasumsikan dengan random variability hariannya sebesar $10 \%$.

b) Data masukan Biomassa 
OPTIMASI KAPASITAS PEMBANGKIT LISTRIK TENAGA HIBRIDA MENGGUNAKAN HOMER DI TPA GAMPONG JAWA BANDA ACEH Mahdi Syukri, Dedy Yuliadi, Syahrizal

Setelah Data didapat dari hasil wawancara kemudian dimasukkan ke dalam database HOMER. HOMER dapat memberikan informasi berupa total biomassa yang digunakan dan akan dimasukkan sebagai parameter yang akan disimulasikan kedalam sistem PLTH.

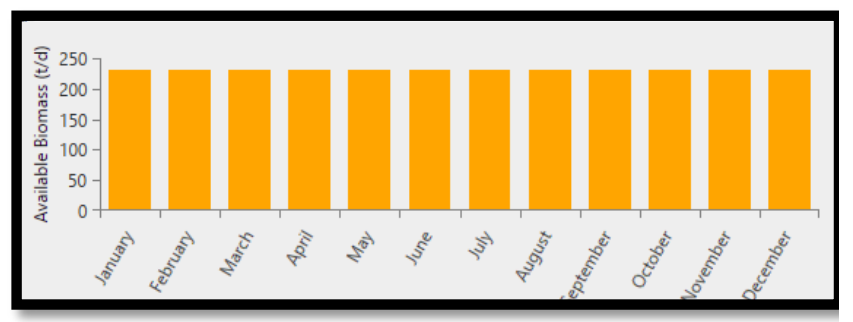

Gambar 3 Profil Data Biomassa

c) Data Masukan Radiasi Matahari

Pada proses simulasi untuk mengetahui potensi radiasi matahari pada suatu tempat, HOMER memerlukan informasi latitude dan longitude dari tempat tersebut. Latitude dan longitude disimulasikan oleh HOMER sehingga mendapatkan pola radiasi yang sesuai. Latitude dan longitude daerah penilitian adalah $5^{\circ} 58^{\prime}$ dan 95²6’ yang merupakan lokasi yang beradai di sekitar TPA Gampong Jawa Banda Aceh.

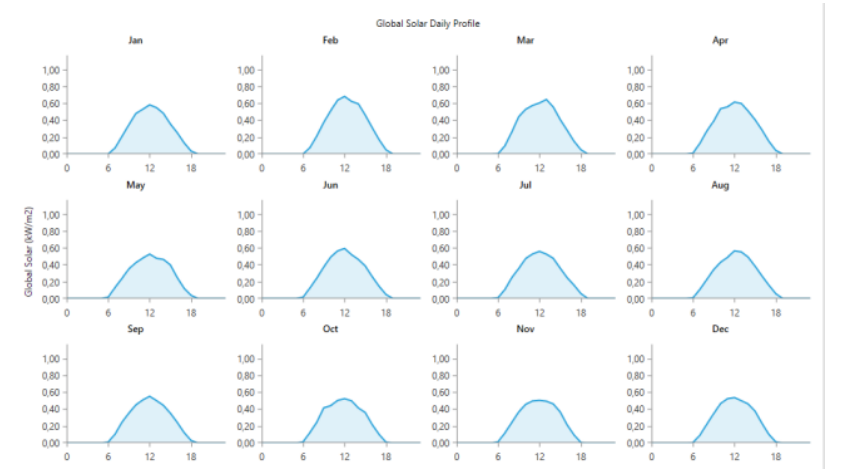

Gambar 4 Radiasi matahari per-jam

Pada gambar 4 diatas menjelaskan bahwa radiasi matahari hanya ada disetiap siang hari.
Jurnal Geuthèë: Penelitian Multidisiplin Vol. 04, No. 01, (April, 2021), pp. 10-17.

Radiasi matahari ada pada pukul 06.00 WIB dan terus meningkat hingga pukul 12.00 WIB lalu mulai turun sampai pada pukul 18.00 WIB.

d) Pemodelan sistem PLTH

Pemodelan sistem pembangkit listrik tenaga hibrida dilakukan untuk menjalankan software HOMER, dimana di dalam pemodelan tersebut yang merupakan komponen-komponen dasar mendukung proses simulasi pembangkit listrik tenaga hibrida tersebut. Ada tiga skenario yang dilakukan untuk mengetahui sistam hibrid yang mana yang lebih optimal.

\section{1) Skenario 1}

Skenario 1 dimana skema yang terdiri hanya dari Generator yang untuk memenuhi beban dapat dilihat pada gambar 5

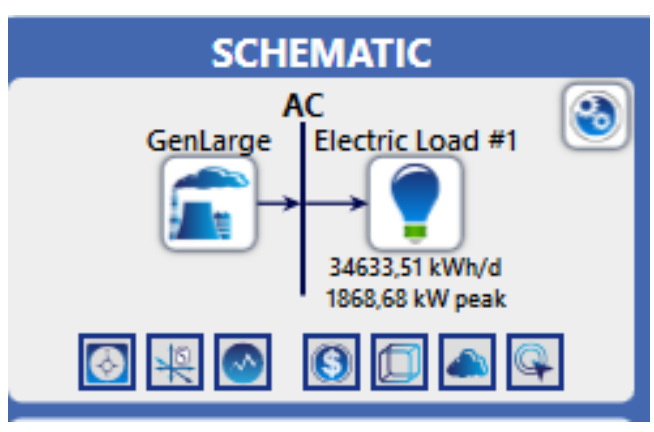

Gambar 5 Skenario 1

\section{2) Skenario 2}

Skenario 2 dimana skema yang terdiri menggunakan $p v$,baterai, dan konverter dapat dilihat pada gambar 6 . 


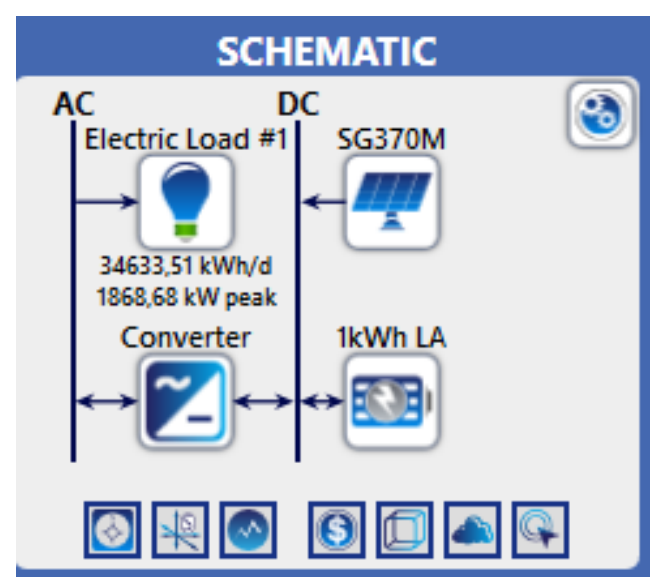

Gambar 6 Skenario 2

\section{3) Skenario 3}

Skenario 3 dimana skema pembangkit tenaga hybrid dimana perhitungan dilakukan oleh software HOMER dapat dilihat pada gambar 7 .

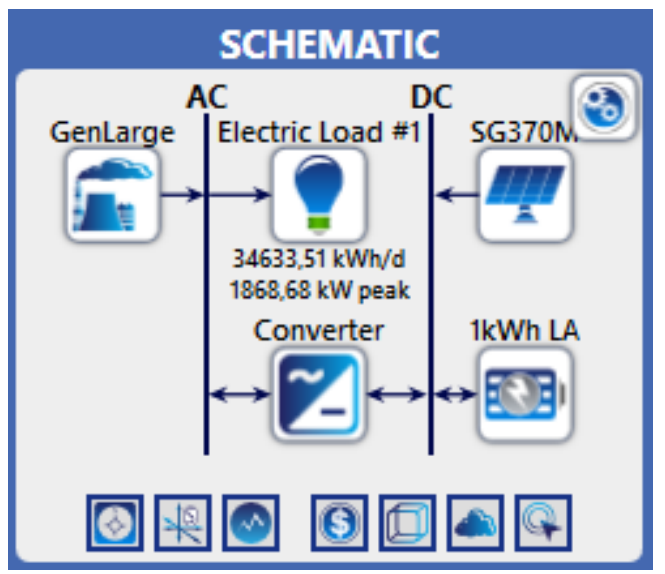

Gambar 7 Skenario 3

\section{HASIL PENELITIAN DAN PEMBAHASAN}

\section{1) Skenario 1}

Hasil simulasi yang didapatkan dari software HOMER ini merupakan sistem optimasi berdasarkan komponen-komponen dan parameter yang telah dimasukkan ke dalam sistem PLTH. Setelah semua komponen dan parameter yang telah dimasukkan maka akan didapatkan hasil optimasi yang sesuai berdasarkan sensitivitas yang telah ditentukan.

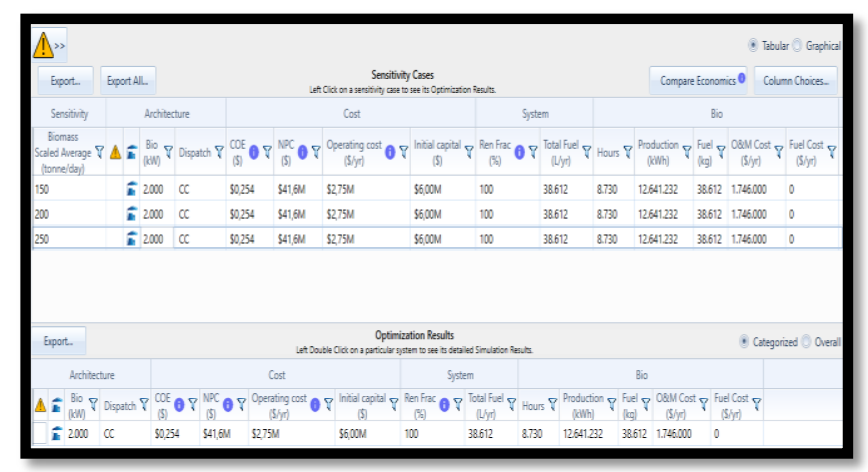

Gambar 8 Hasil dari Skenario 1

Tabel 2 Produksi Energi skenario 1

\begin{tabular}{|c|c|c|}
\hline Produksi & $\mathrm{kWh} /$ tahun & $\%$ \\
\hline $\begin{array}{c}\text { Generic } \\
\text { Biogas }\end{array}$ & 12.641 .232 & 100 \\
\hline Total & 12.641 .232 & 100 \\
\hline
\end{tabular}

\section{2) Skenario 2}

Hasil simulasi yang didapatkan dari software HOMER ini merupakan sistem optimasi berdasarkan komponen-komponen dan parameter yang telah dimasukkan ke dalam sistem PLTH. Setelah semua komponen dan parameter yang telah dimasukkan maka akan didapatkan hasil optimasi yang sesuai 
OPTIMASI KAPASITAS PEMBANGKIT LISTRIK TENAGA HIBRIDA MENGGUNAKAN HOMER DI TPA GAMPONG JAWA BANDA ACEH

Mahdi Syukri, Dedy Yuliadi, Syahrizal
Jurnal Geuthèë: Penelitian Multidisiplin Vol. 04, No. 01, (April, 2021), pp. 10-17.

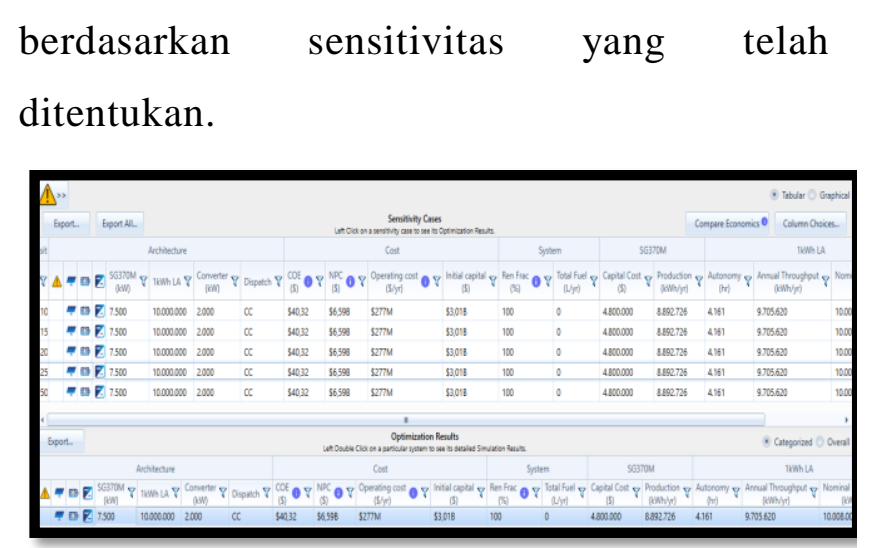

Gambar 9 Hasil dari Skenario kedua

Tabel 3 Produksi Energi Skenario kedua

\begin{tabular}{|c|c|c|}
\hline Produksi & $\mathrm{kWh} / \mathrm{tahun}$ & $\%$ \\
\hline $\begin{array}{c}\text { Peimar } \\
\text { SG370M }\end{array}$ & 8.892 .726 & 100 \\
\hline Total & 8.892 .726 & 100 \\
\hline
\end{tabular}

\section{3) Skenario 3}

Hasil simulasi yang didapatkan dari software HOMER ini merupakan sistem optimasi berdasarkan komponen-komponen dan parameter yang telah di masukan ke dalam sistem PLTH. Setelah semua komponen dan parameter telah dimasukan maka akan didapatkan hasil optimasi yang sesuai berdasarkan sensitivitas yang telah ditentukan.

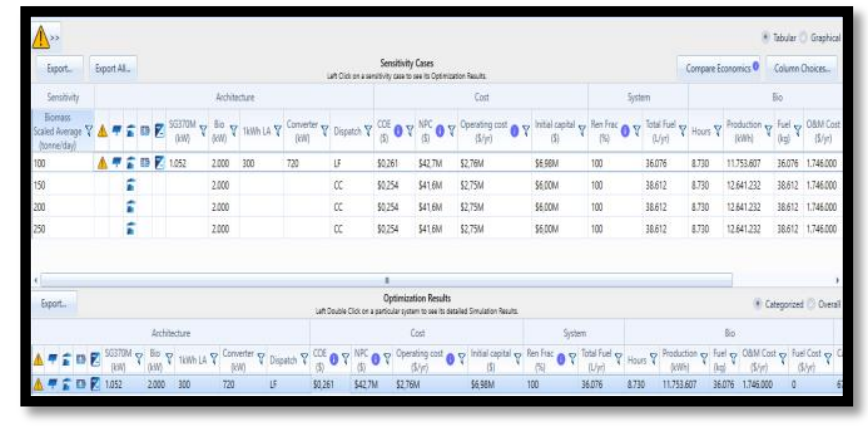

Gambar 9 Hasil dari Skenario ketiga

Tabel 4 Produksi Energi Skenario 3

\begin{tabular}{|c|c|c|}
\hline Produksi & $\mathrm{kWh} /$ tahun & $\%$ \\
\hline $\begin{array}{c}\text { Peimar } \\
\text { SG370M }\end{array}$ & 1.248 .080 & 9,60 \\
\hline $\begin{array}{c}\text { Generic } \\
\text { Biogas }\end{array}$ & 11.753 .607 & 90,4 \\
\hline Total & 13.001 .687 & 100 \\
\hline
\end{tabular}

\section{KESIMPULAN}

1. Potensi Daya listrik dari pembangkit biomassa di TPA Gampong Jawa, yaitu $2.000 \mathrm{~kW}$ dengan menggunakan data dari HOMER dengan produksi Sampah 250 ton dan dapat dapat menghasilkan jumlah energi listrik dalam setahun 12.641.232 kWh/tahun

2. Model pembangkit yang paling optimal adalah skenario 3 dilihat dari segi ekonomis NPC dan COE, yaitu NPC \$42.698.527 dan COE $\$ 0,2614$, dimana biomassa 11.753.607 kWh/tahun, PV 1.248 .080 kWh/tahun, Generic $1 \mathrm{kWh}$ Lead Acid 300 unit, dan konverter $720 \mathrm{~kW}$. 


\section{DAFTAR PUSTAKA}

[1] Md Saleh Ebn Sharif, Md Monower Zahid Khan, Md Moniruzzaman, and Anamika Bose "Design, Simulation and Stability Analysis of Wind-PV-Diesel Hybrid Power System Using ETAP"American Journal of Modern Energy, Vol. 3, No. 6, pp. 121-130, November 2017

[2] A. Giwa, A. Alabi, A. Yusuf, and T. Oluka, "A comprehensive review on biomass and solar energy for sustainable energy generation in Nigeria” Renew. Sustain. Energy Rev., vol. 69, pp. 620-641. 2017

[3] E. Romero-Cadaval, B. Francois, M. Malinowski, and Q. C. Zhong, "Grid-connected photovoltaic plants: An alternative energy source, replacing conventional sources," IEEE Ind. Electron. Mag., vol. 9, no. 1, pp. 18-32. 2015.

[4] Haryanto, "Optimasi pembangkit hybrid PLN-Solar pada aplikasi home in dustry," Skripsi Magister Teknik Elektro. Yogyakarta, Indonesia, 2018.

[5] Tanim, M., Chowdhury, N.A., Rahman, M.M., Ferdous, J., others, "Design of a photovoltaicbiogas hybrid power generation system for bangladeshi remote area using HOMER software," dalam: Developments in Renewable Energy Technology (ICDRET), International Conference on the. IEEE, pp. 1-5. 2014.

[6] Peraturan Presiden Republik Indonesia No. 5 Tahun 2006 tentang Kebijakan Energi Nasional. 